Article

\title{
The legal and the epistemic in times of techno-scientific transformation: Inefficacies of
} JTB account of knowledge

Dimitris Kilakos ${ }^{1, *}$, Stela Papaoikonomou ${ }^{2}$

${ }^{1}$ Post-doctoral Fellow, Sofia University "St. Kliment Ohridski", Faculty of Philosophy; Adjunct Lecturer, University of West Attica, Dept. of Informatics and Computer Engineering ; dkoilakos@uniwa.gr

2 Independent Researched; stela.papaoikonomou@gmail.com

* Correspondence: dkoilakos@uniwa.gr

\begin{abstract}
Echoing the long-held JTB account of knowledge, according to which knowledge can be conceptually analyzed as justified true belief, Backes (2019) argues that our epistemic aim is to believe truly or accurately and emphasizes on that "a belief is justified iff it is highly probable". We maintain that this line of reasoning is deficient, in terms of epistemic concerns and non-epistemic concerns of interest for both philosophy and legal theory. Specifically, in this short paper, we argue for the ineffectiveness of the aforementioned Backes' view to meet the challenges posed by the ongoing rapid techno-scientific transformation of our contemporary societies and ways-of life.
\end{abstract}

Keywords: JTB account on knowledge; Gettier problems; contextualization of belief and knowledge; evidence; epistemic and non-epistemic dimensions of law

\section{Introduction}

Echoing the long-held JTB account of knowledge, according to which knowledge can be conceptually analyzed as justified true belief, Backes (2019) argues that our epistemic aim is to believe truly or accurately and emphasizes on that "a belief is justified iff it is highly probable". We maintain that this line of reasoning is deficient, both in terms of epistemic concerns per se and of implications for legal theory. The latter may seem surprising. However, it is relevant, since it has been argued that the law transcends the epistemic domain, given that it also has a non-epistemic dimension: the law is not only concerned with reaching true verdicts, since these verdicts should also be just and fair (Backes 2019; Tribe 1971, p. 1376; Saks and Kidd 1980-1981, p. 125). Therefore, the potential fruitfulness of exploring the non-epistemic dimension of law depends on the scope of our explorations on its epistemic dimension, which, in turn, depends on our conception of the epistemic domain. In this short paper, we attempt to circumscribe the aforementioned epistemic concerns and their implications for legal theory, by arguing for the ineffectiveness of the aforementioned Backes' view to meet the challenges posed by the ongoing rapid techno-scientific transformation of our contemporary societies and ways-of life. We deploy in argumentation in the two following sections which precede our concluding remarks. In the first of these two sections, we address epistemic concerns from a philosophical and jurisprudential perspective, while in the second one we address relevant aspects of the problem of contextualisation of belief, knowledge and their justification in the light of the discussion on JTB account of knowledge and Gettier problems. In both of these sections, we discuss several cases and examples of interest with regard to the ongoing techno-scientific transformations of our contemporary societies and their practical impact.

\section{Epistemic concerns from a philosophical and jurisprudential perspective}


As mentioned previously, Backes (2019) argues that "a belief is justified iff it is highly probable". Let us scrutinize on this view. If its probability is the only (or, at least, the best available) means at our disposal in order to justify a certain belief, then improbable beliefs are rendered unjustified. However, such a contention is problematic, at least for two reasons: i) it is not in par with modern science and techno-scientific advancements, and ii) it misguides the discussion on the inherent social dimension of human cognition.

With regard to modern science, one could point to quantum theory, in the domain of which less probable events and states are observable outcomes of several processes and the distribution of their probabilities is epistemically significant. One could counterargue that this is not a matter of belief but of the inherent features of the domain of quantum theory. However, if our belief in the accuracy of the theoretical appropriation of evidence is substantially undermined in a single domain, then there should be a clear-cut distinction, rendering it a priori incompatible with any other. If such a distinction is not available, then the prospects of Backes' assertion are blurred, since there could be no inclusive account grounded on it. Thus, one should appeal to different accounts for belief and its justificatory status in the cases of legal theory and natural sciences, for example. Of course, this might not be a problem for legal positivism or positivistic conceptions of science; however, the fruitfulness of such stances in anything but undisputed. While this is not the proper venue to discuss whether the integration of scientific knowledge is an attainable or covetable cause, an issue on which there is a longstanding and still vivid discussion, it suffices for our current purpose to highlight that, as it has been recently argued, while the public discussion often pits the disciplines against one another, the sciences, arts, and humanities are - as Albert Einstein once wrote - "branches of the same tree" (Skorton 2019, p. 1865).

With regard to techno-scientific advancements, if one is to endorse Backes' view, then it should be contextualized and/or deflated in order to account for 'virtual' and 'augmented' reality. A belief that could be justified by appealing to its high probability with regard to nature, may be disputed in a 'virtual' or 'augmented' context in which it may become highly improbable - and vice versa. Of course, in such a case, it may not the belief that becomes contextualized, but its justification, which becomes more or less probable in the given context. The same could also be argued for the probability of any justification, which may decrease or increase in several contexts. However, since we focus on epistemic concerns in this paper, it should be clear that it is knowledge that becomes contextualized in any of the aforementioned cases, inasmuch as one endorses JTB account of knowledge, which is echoed by Backes' views, according to which knowledge amounts to justified true belief. Therefore, the issue of truth -or even truthlikeness or verisimilitude, in the sense Niiniluoto (1987) addresses the issue- inevitably comes forth.

Another problem is highlighted by the following hypothetical example. Suppose that a store was burgled, but there was no eye-witness to identify the burglar, as well as there were no fingerprints or DNA or anything else retrieved from the field that might help the police to identify the burglar. However, the surveillance camera made it possible for the police to have a photo of the burglar. Thus, the officers ran a facial recognition program, which contrasted and compared the photo with photos of several persons who had been arrested in the past. The program matched the photo from the surveillance camera with one of the other photos, but the accuracy was not more than $80 \%$. It is not a near-perfect match, but arguably sufficient to lead to the purported suspect's arrest. The suspect is brought in the interrogation room, but the officers, who have no other clue in 
hand, do not manage to extract a confession, since the suspect firmly denies the accusation. Does this partial recognition, which is a fact, count as sufficient evidence to further prosecute and, eventually, convict the suspect, beyond any reasonable doubt, without further evidence? Could it justify a belief on the suspect's guilt, on the grounds that $80 \%$ accuracy means that this specific partial identification is highly probable to point to a correct one? Would there be any difference if the aforementioned accuracy was $70 \%$ or $90 \%$ - but, in any case not a perfect match? It is arguably extremely difficult to proffer a solid argumentation to account for a positive answer to these questions. Moreover, in such highly probable but not absolutely certain identifications by technological means, without any further evidence, how could one a priori exclude the possibility of biased prosecutions, i.e. if the suspect belongs to a racial minority? For, it is arguably unanimously accepted that minorities may be more vulnerable to arbitrary attitudes against them by law-enforcement officials. Therefore, we maintain that a justified, on the grounds of a highly probable yet partial identification by technological means, belief on someone's guilt is arguably not a solid epistemic underpinning for juridical reasons.

\section{Philosophical and jurisprudential aspects of the problem of contextualisation of belief,}

\section{knowledge and their justification}

To be clear, contextualization of knowledge is not a problem per se; indeed, it is necessary to be able to trace the mutual interaction of the context in which knowledge is produced and advances with its content and the outcomes of the several modes of human -social and individual- activity which is informed by it. However, it is a matter of fierce dispute if it inevitably leads to relativism and/or perspectivism about truth, and/or to social contructivism (or constructionism) of any kind in general. For example, contrary to any of these views, it has been efficiently and effectively argued from a marxist point of view that "all progress in our knowledge comes down to bringing what was previously 'unthinkable' within the ambit of our thought: we find, see, and comprehend" (llyenkov 2007, p. 24) - obviously, what we find, see and comprehend and how we do it, depends on the context in which we do it.

Interestingly, Ilyenkov deploys this view in an attempt to criticize views that reduce knowledge to a system of propositions. Thus, it could spearhead attempts to undermine JTB account of knowledge, which arguably represents the most typical understanding of typical knowledge, without appealing to Gettier problems, to which those who attempt to repudiate it usually appeal, in the context of analytical epistemology. In short, Gettier problems are counterexamples used to prove that it is possible one to hold a justified, true belief regarding a claim but still fail to know it, since the reasons for the belief, while justified, may be false. Thus, the JTB account is rendered inadequate in the light of Gettier problems, since it does not account for all of the necessary and sufficient conditions for knowledge (for an overview of this discussion, see i.e. Williamson, 2000; Lycan, 2006). In fact, Ilyenkov and other marxists manage to address these and other issues by transcending analytical epistemology and disputing its foundations.

This is also important from a jurisprudential perspective, since the longstanding philosophical discussion on JTB account has raised issues relevant to epistemic concerns of interest for legal theory. For example, it has been argued that knowledge is not what inquirers should seek (Kaplan 1985). 
However, if it is not knowledge, then what is it that truth-value could be ascribed to? Irrespectable to the purported dissonance between the philosophical and the legal discourse on truth, the answer to this question may inform the discussion on whether truth is subservient to justice and on truth or proof is the justice system's main concern (Fernandez, 2009), as well as the context of the discussion on truth in law and the purported distinction between substantive and legal truth (i.e. Coleman, 1995; Patterson, 1996; Haack, 2003). Furthermore, the discussion on Gettier cases and their interpretations is argued to depend on a conception of knowledge with skeptical implications (Kirkham, 1984). Thus, the aforementioned discussion may inform the discourse on skeptical theories of legal interpretation and skeptical approaches to the defeasibility issue (i.e. Chiassoni, 2019), as well as the discussion on the theoretical assumptions underpinning the process of fact-finding and evidence discourse in relation to truth, reason and justice (i.e. Nicolson, 1994).

Another example of contextualisation of belief, justification and probability is provided by the discussion on the so-called 'conspiracy theories' and their dissemination in social media. Those who endorse 'conspiracy theories' justify their belief in them by appealing to the likelihood of their content to be valid, as indicated by whatever they conjure up to confirm them - this may be circumstantial evidence, misleading indications, explanatory gaps in other narratives on the issue etc. While this is not the proper venue to address the issue in detail, it should be mentioned that the discussion on the rationality or irrationality of conspiracy theories is pertinent to the discussion on their justificatory status and on their epistemic acceptability (cf. Coady, 2007; Goertzel, 1994; Räikkä, 2014). An important aspect of the discussion on 'conspiracy theories' regards the kind(s) of evidence that may serve for the justification of beliefs which inform actions by several social agents, as well as the discussion on if and how non-epistemic factors should be engaged in any account on truth. These aspects are of interest from a jurisprudential perspective, on the aforementioned grounds.

While what is said thus far may be counted as relevant to jurisprudential perspective only with regard to the epistemic dimension of law, we maintain that it is also relevant to its non-epistemic dimension. For example, a verdict to be just and fair, next to any social context that renders it so, it should be grounded on evidence that justifies the belief to its justice and fairness. Thus, even if appealing to the non-epistemic dimension of law may seem trivial, taken at face-value, it becomes highly contextual and, what is more, even highly problematic, once one bears in mind the challenges against the JTB account of knowledge which underpins Backes' view we argued for thus far.

\section{In lieu of conclusion}

A detailed discussion on whether epistemic and non-epistemic dimensions of law should be envisaged by legal theory is beyond our concerns for this paper. In fact, to be fair with those who endorse views similar to those we have discussed, we co-sign the need to explore the non-epistemic dimensions of law, since we maintain that this line of reasoning may become fruitful for anyone who attempts to contrast the many faces of legal positivism. However, we maintain that any such attempt is not viable on the grounds of Backes' view or the JTB account of knowledge which underpins it. On 
the contrary, as we attempted to argue, there are other options available for anyone who wishes to deploy an account on both the epistemic and the non-epistemic dimensions of law, in which the philosophical perspective does not conflict with the legal one.

It is our strong and, to our view, justified belief, that this is the best available option for anyone who wishes to address the challenges posed by the rapid ongoing techno-scientific transformations and their implications in our contemporary societies and ways-of-life.

Author Contributions: Conceptualization, Dimitris Kilakos and Stela Papaoikonomou; methodology, Dimitris Kilakos; investigation, Dimitris Kilakos and Stela Papaoikonomou; writing-original draft preparation, Dimitris Kilakos and Stela Papaoikonomou; writing-review and editing, Dimitris Kilakos and Stela Papaoikonomou; supervision, Dimitris Kilakos. All authors have read and agreed to the published version of the manuscript.

Funding: This research received no external funding.

Conflicts of Interest: The authors declare no conflict of interest.

\section{References}

1. Backes, M. (2019). Epistemology and the law: why there is no epistemic mileage in legal cases. Philosophical Studies. https://doi.org/10.1007/s11098-019-01337-6

2. Chiassoni, P. (2019). Interpretation without truth. New York: Springer International Publishing.

3. Coady, D. (2007). Are Conspiracy Theorists Irrational?. Episteme, 4(2), pp. 193-204.

4. Coleman, J.(1995). Truth and Objectivity in Law. Legal Theory, 1(1), pp.33-68.

5. Fernandez, J.M. (2009). An exploration of the meaning of truth in philosophy and law. The University of Notre Dame Australia Law Review, 11, pp. 53-83.

6. Goertzel, T. (1994). Belief in Conspiracy Theories. Political Psychology, 15(4), pp. 731-742.

7. Haack, S. (2003). Truth, truths, "truth," and "truths" in the law (2003). Harvard Journal of Law \& Public Policy, 26, pp. 17-21.

8. Ilyenkov, E.V. (2007). Our Schools Must Teach How to Think!. Journal of Russian and East European Psychology, 45(4), pp. $9-49$.

9. Kaplan, M. (1985). It's Not What You Know That Counts. Journal of Philosophy, 82, pp. 350-363.

10. Kirkham, R. L. (1984). Does the Gettier Problem Rest on a Mistake?. Mind, 93, pp. 501-13.

11. Lycan, W. G. (2006). On the Gettier Problem Problem. In: Epistemology Futures, (ed.) S. Hetherington (pp. 148-168). Oxford: Oxford University Press.

12. Nicolson, D. (1994). Truth, Reason and Justice: Epistemology and Politics in Evidence Discourse. Modern Law Review, 57 (5), pp. 726-744.

13. Niiniluoto, I. (1987). Truthlikeness. Dordrecht: Springer Netherlands.

14. Patterson, D. (1996). Law and Truth. New York: Oxford University Press.

15. Räikkä J. (2014). On the Epistemic Acceptability of Conspiracy Theories. In: Social Justice in Practice. Studies in Applied Philosophy, Epistemology and Rational Ethics, vol 14. New York: Springer, pp. 61-75

16. Saks, M., \& Kidd, R. (1980-1981). Human information processing and adjudication: Trial by heuristics. Law and Society Review, 15(1), pp. 123-160.

17. Skorton, D. (2019). Branches from the same tree: The case for integration in higher education. Proceedings of the National Academy of Sciences, 116 (6), pp. 1865-1869.

18. Tribe, L. (1971). Trial by mathematics: Precision and ritual in the legal process. Harvard Law Review, 84(6), pp. 1329-1393.

19. Williamson, T. (2000). Knowledge and Its Limits. Oxford: Oxford University Press.

(c) 2020 by the authors. Submitted for possible open access publication under the terms and conditions of the Creative Commons Attribution (CC BY) license (http://creativecommons.org/licenses/by/4.0/). 